\title{
Postpartum Obstetric Patients in Tertiary Level Intensive Care Unit: To Study Their Clinical Characteristics, Prevalence, Outcome and to Compare Prognostic Scores Mews with Apache II
}

\author{
Vidula Bansal, Zia Arshad* and Singh GP \\ Department of Anesthesiology and Critical Care, King George's Medical University, India
}

Submission: October 09, 2019; Published: November 13, 2019

*Corresponding author: Zia Arshad, Department of Anesthesiology and Critical Care, King George's Medical University, Lucknow, India

\begin{abstract}
Objective: In this study, we studied the clinical characteristics and compared prognostic scores MEWS with APACHE II on postpartum obstetric patients admitted in tertiary level.

Materials and Methods: We conducted a prospective, observational study for one year on 160 patients admitted to a tertiary level ICU. Their diagnosis, clinical interventions and final outcome were noted. MEWS and APACHE II scores were evaluated on admission, ROC curve was plotted and Area Under Curve was evaluated.

Results: Mean age of admission was $26.16 \pm 4.88$ years. Most common diagnosis leading to admission was Pregnancy induced Hypertension (19.4\%) and least common was molar pregnancy (1.9\%). Pregnancy Induced Hypertension, Post-Partum Hemorrhage had adverse whereas ectopic pregnancy, anemia and heart disease had good prognosis. The most common obstetric surgical intervention was LSCS and least common was D\&C and laparotomy. Mortality plus morbidity rate was $9.4 \%$. Mean duration of mechanical ventilation of patients with adverse and good outcome was $6.54 \pm 5.69$ and $1.96 \pm 1.41$ days respectively. The use of NDMR and inotropes were associated with an adverse prognosis. Transfusion of blood products had no significant correlation with outcome. An APACHE II $>15$ and MEWS $>6.5$ were associated with adverse outcomes. MEWS had more Area Under Curve than APACHE II on ROC curve. MEWS score had a better sensitivity and specificity than APACHE II.
\end{abstract}

Conclusions: Pregnancy Induced Hypertension was major cause of postpartum obstetrical ICU admissions and it had an adverse prognosis overall. MEWS is a better indicator of prognosis than APACHE II in critically ill obstetric patients.

Keywords: Obstetric; critical care; MEWS; APACHE II

\section{Introduction}

Critically ill obstetric patients when admitted to the Intensive Care Unit are a challenge to the intensivist mainly because of the changed physiology [1]. The prevalence of ICU obstetric admissions is $0.1-0.9 \%$ of the total deliveries [1]. Maternal mortality in the ICU varies 3.4-21\% [1]. Clinicians and researchers require scores for mortality prediction in critically ill patients, and multiple scoring systems have been developed for this purpose in both the emergency department (ED) and the intensive care unit (ICU) [2]. It remains unknown which of these scores perform best in ICU patients [2]. The Acute Physiology and Chronic Health Evaluation II score (APACHE II) is the most widely used and most studied of the critical care outcome prediction models in obstetric patients [3]. An APACHE II score of 20 points is the cutoff point for severity $[4,5]$. MEWS has been validated in several critically ill patients and showed that it could predict mortality
[6]. Some studies have shown that a MEWS of at least five out of the maximum score of 15 is associated with a greater risk of ICU admission and poor outcome [7]. Failure to identify early signs of illness in obstetric patients has been a recurrent feature of maternal deaths and serious morbidity which is an indicator of health care system of the country.

\section{Materials and Methods}

This prospective observational study was conducted in ICU managed by anesthesiologists under a 4500 bedded tertiary care hospital in northern India. A total of 9563 (4685 Vaginal and 4878 Caesarean) deliveries took place during the study period of one year, out of which 160 patients who required ICU admission were studied. All post-partum women within 42 days of delivery requiring ICU admission for obstetric, non-obstetric reasons, 
irrespective of age, parity, mode of delivery and comorbid conditions were included in the study. Patients requiring ICU admission after 42 days of delivery and patients being discharged before 24 hours of admission were excluded from the study. All patients were studied in terms of their demographic profile, diagnosis with any preexisting comorbidity, immediate pathological condition for admission in the ICU, obstetrical and anesthetic interventions, ventilatory requirements, end organ failure or complication during the ICU stay and final outcome in terms of discharge, morbidity or mortality. Also, on admission till 24 hours APACHE II and MEWS score was calculated for all the patients. The area under the receiver operating characteristic curve (AUC), with a 95\% confidence interval (CI), was used to evaluate the discrimination performance of each score. The sensitivity and specificity were calculated for each score. The statistical analysis using SPSS (Statistical Package for Social Sciences) Version 21.0 statistical Analysis Software was used. The values were represented in Number (\%) and Mean \pm SD. Chi Square test and Student ' $\mathrm{t}$ ' test were used. For sample size calculation, we used the study by Jain et al. [8], according to it prevalence of obstetric ICU admissions was $0.9 \%$. By calculation, sample size came out to be 138 . During our study period, post-partum obstetric patients who required ICU admission, whose attendants gave consent and fulfilled inclusion criteria came out to be 160 .

\section{Results}

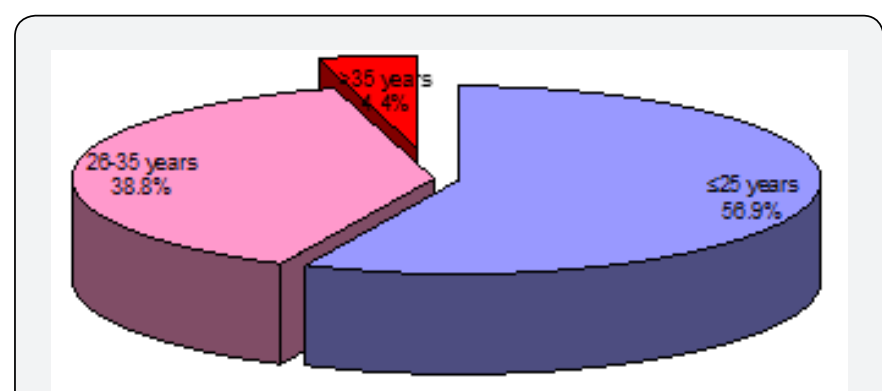

Figure 1: Distribution of Study Population ( $\mathrm{N}=160)$ according to age.

Out of the 160 patients enrolled in our study, mean age of patients was $26.16 \pm 4.88$ years. Majority of the patients were aged $\leq 25$ years $(56.9 \%)$, only $7(4.4 \%)$ were above 35 years of age and rest $38.8 \%$ patients were aged 26-35 years. Association of age and outcome was not found to be statistically significant. Most common diagnosis was pregnancy induced hypertension (19.4\%) followed by ante-partum hemorrhage (15.6\%). Least common diagnosis was septic abortion/encephalopathy (2.5\%) and Pulmonary embolism/dengue (1.9\%). Adverse outcome was higher as compared to good outcome among patients diagnosed as PIH (33.3\% vs. 17.9\%), PPH (20.0\% vs. 6.9\%), Septic abortion/encephalopathy ( $26.7 \%$ vs. $0.0 \%$ ) while proportion of patients with good outcome was higher as compared to adverse outcome for rest of the diagnosis. This difference was found to be statistically significant (Figure 1). Out of 160 patients in the study, most common immediate cause of ICU admission was hemorrhagic shock or anemia with 92 patients (57.5\%) followed by ventilatory support or monitoring with 51 patients $(31.8 \%)$. 33 patients $(20.6 \%)$ reported to have other medical comorbidities (GDM, heart disease, hypothyroidism, Diabetes, CKD, Uterine tuberculosis, Mitral stenosis, Polio). However, they did not have any statistical significance with outcome. 145 (90.6\%) patients were discharged without comorbidity (good outcome), 5 (3.1\%) discharged after renal failure and 10 (6.3\%) expired before discharge (adverse outcome). Proportion of adverse outcome was higher among patients in whom no intervention was done $(13.3 \%$ vs. $0.0 \%)$ and who were vaginally delivered $(20.0 \%$ vs. $2.8 \%$ ) while proportion of good outcome was for LSCS (80.0\% vs. $60.0 \%)$, Salpingectomy (13.8\% vs. $6.7 \%$ ) and other interventions ( $3.4 \%$ vs. $0.0 \%$ ). This difference was found to be statistically significant (Table 1).

Table 1: Distribution of study population $(\mathrm{N}=160)$ according to immediate cause for ICU admission.

\begin{tabular}{|c|c|c|c|}
\hline SN & $\begin{array}{c}\text { Immediate Cause for Icu } \\
\text { Admission }\end{array}$ & $\begin{array}{c}\text { Number of } \\
\text { Subjects }\end{array}$ & Percentage \\
\hline 1 & Hemorrhagic shock/Anaemia & 92 & 57.5 \\
\hline 2 & Ventilatory Support/Monitoring & 51 & 31.8 \\
\hline 3 & MODS & 3 & 1.8 \\
\hline 4 & Renal Insufficiency & 3 & 1.8 \\
\hline 5 & Respiratory Insufficiency & 10 & 6.2 \\
\hline 6 & Neurological Insufficiency & 1 & 0.6 \\
\hline
\end{tabular}

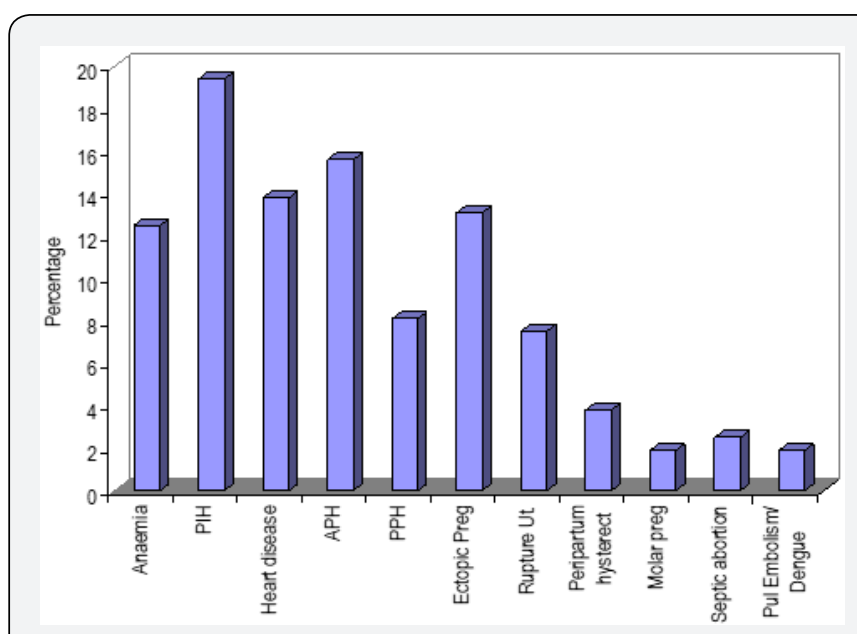

Figure 2: Distribution of Study Population ( $N=160)$ according to Definitive Diagnosis.

Out of the 44 patients who received mechanical ventilation for less than 1 day, 42 patients had good outcome and 2 patients had adverse outcome. Mean duration of mechanical ventilation of patients with adverse outcome (6.54 \pm 5.69 days) as compared to those with Good outcome (1.96 \pm 1.41 days) was found to be significantly higher. Proportion of patients with Adverse outcome was found to be significantly higher as compared to those with Good outcome, who used NDMR (66.7\% vs. $2.8 \%$ ), used Inotropic drugs $(100.0 \%$ vs. $40.0 \%)$ or had End organ damage 
(86.7\% vs. 4.8\%). Proportion of patients with adverse outcome was higher as compared to those with Good outcome who required blood products during hospital stay ( $86.7 \%$ vs. $40.0 \%$ ) but this difference was not found to be statistically significant. Patients with Adverse outcome as compared to those with Good Outcome had significantly higher prognostic scores i.e. MEWS score $(8.20 \pm 2.62$ vs. $3.76 \pm 2.38)$ and APACHE II (19.20 \pm 5.19 vs. $12.60 \pm 5.03$ ) (Figure 2). ROC for both the prognostic indicators (APACHE-II and MEWS) were drawn to predict mortality as well as Adverse outcome (mortality + morbidity). Area under curve on ROC for APACHE-II and MEWS to predict the mortality were 0.811 $\& 0.863$. APACHE-II $>17.50$ was found to be $80.0 \%$ Sensitive and $80.5 \%$ specific to predict mortality, while MEWS $>6.50$ was found to be $90.0 \%$ sensitive; $82.6 \%$ specific to predict mortality. Area under curve for APACHE-II and MEWS for prediction of adverse outcome (Mortality + Morbidity) were 0.822 \& 0.888 . APACHEII $>17.50$ was found to be $80.0 \%$ Sensitive and $82.4 \%$ specific to predict adverse outcome while MEWS $>6.50$ was found to be $86.7 \%$ sensitive; $84.7 \%$ specific to predict adverse outcome (Table 2). Proportion of patients with Good outcome was higher as compared to Adverse outcome having APACHE-II score up to 14 i.e. $0-4$ (2.1\% vs. $0.0 \%$ ), $5-9$ (29.0\% vs. $6.7 \%$ ), $10-14$ (37.9\% vs. 6.7\%) while proportion of patients with Adverse outcome was higher as compared to Good outcome having APACHE-II score $\geq 15$ i.e. $15-19$ ( $46.7 \%$ vs. $19.3 \%$ ), $20-24$ (20.0\% vs. $9.7 \%$ ), 25-29 (20.0\% vs. 1.4\%). Association of Outcome and APACHEII score was found to be statistically significant. Majority of the patients having Good outcome had MEWS score <6.50 (84.8\%) while majority of the patients having Adverse outcome had MEWS score $\geq 6.50(86.7 \%)$. This association was found to be statistically significant (Figure 3).

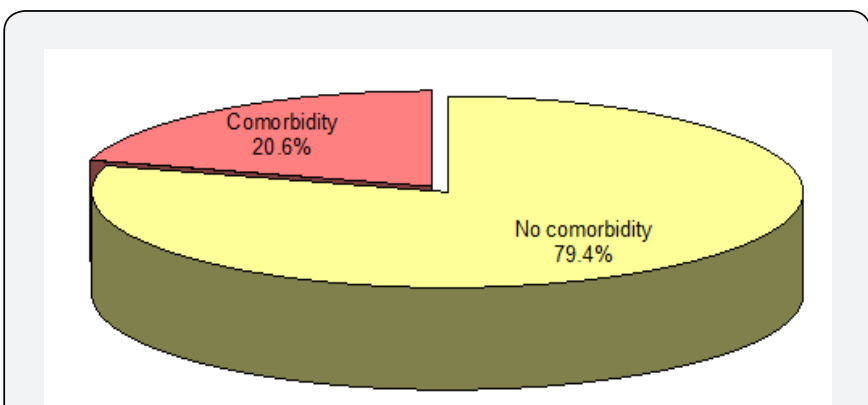

Figure 3: Distribution of Study Population ( $N=160)$ according to other medical comorbidities.

Table 2: Association of Outcome and Diagnosis among Study Population.

\begin{tabular}{|c|c|c|c|c|c|c|}
\hline \multirow{2}{*}{ SN } & \multirow{2}{*}{ Comorbidity } & \multirow{2}{*}{ Total $(\mathrm{N}=160)$} & \multicolumn{2}{|c|}{ Good Outcome $(n=145)$} & \multicolumn{2}{|c|}{ Adverse Outcome $(n=15)$} \\
\hline & & & No. & $\%$ & No. & $\%$ \\
\hline 1 & Anaemia & 20 & 20 & 13.8 & 0 & 0.0 \\
\hline 2 & Pregnancy induced hypertension & 31 & 26 & 17.9 & 5 & 33.3 \\
\hline 3 & Heart disease & 22 & 21 & 14.5 & 1 & 6.7 \\
\hline 4 & Ante-partum haemorrhage & 25 & 24 & 16.6 & 1 & 6.7 \\
\hline 5 & Post-partum haemorrhage & 13 & 10 & 6.9 & 3 & 20.0 \\
\hline 6 & Ectopic Pregnancy & 21 & 20 & 13.8 & 1 & 6.7 \\
\hline 7 & Rupture uterus & 12 & 12 & 8.3 & 0 & 0.0 \\
\hline 8 & Peripartum hysterectomy & 6 & 6 & 4.1 & 0 & 0.0 \\
\hline 9 & Molar pregnancy & 3 & 3 & 2.1 & 0 & 0.0 \\
\hline 10 & Septic abortion/ Encephalopathy & 4 & 0 & 0.0 & 4 & 26.7 \\
\hline 11 & Pulmonary Embolism/Dengue & 3 & 3 & 2.1 & 0 & 0.0 \\
\hline
\end{tabular}

$X^{2}=49.353(d f=102) ; p<0.001(N S)$

\section{Discussion}

Table 3: Association of Outcome with Other Anesthetic Interventions.

\begin{tabular}{|c|c|c|c|c|c|c|c|c|}
\hline \multirow{2}{*}{ SN } & \multirow{2}{*}{ Anaesthetic Interventions } & \multirow{2}{*}{ Total $(\mathrm{N}=160)$} & \multicolumn{2}{|c|}{ Good Outcome $(n=145)$} & \multicolumn{2}{|c|}{ Adverse outcome $(n=15)$} & \multicolumn{2}{|c|}{ Significance of Differences } \\
\hline & & & No. & $\%$ & No. & $\%$ & $x^{2}$ & 'p' \\
\hline 1 & NDMR use & 14 & 4 & 2.8 & 10 & 66.7 & 69.536 & $<0.001$ \\
\hline 2 & Requirement of Blood product & 114 & 102 & 70.3 & 13 & 86.7 & 1.791 & 0.181 \\
\hline 3 & Inotropes & 73 & 58 & 40.0 & 15 & 100.0 & 19.726 & $<0.001$ \\
\hline 4 & End organ damage & 20 & 7 & 4.8 & 13 & 86.7 & 83.242 & $<0.001$ \\
\hline
\end{tabular}

The mean age of the critically ill obstetric patients in our study was $26.16 \pm 4.88$ years which correlates with other Indian studies $[9,10,11]$. Age had no correlation with the outcome in

were included in the study both retrospectively and prospectively. Gupta et al. [12] studied 24 patients admitted in their ICU. Study by Purnima Bhat et al. [13] was done over a period of 6.5 years our study. In the study done by Joseph et al. [12], 109 patients during which obstetric patients admitted to the ICU were only 65. 
The large sample size in our study, is because of multiple reasons (Figure 4). Tertiary referral hospital with an 18 bed ICU and lack of an HDU constitute the reasons for the same. Pregnancy induced hypertension $(19.4 \%)$ was the most common obstetric cause of admission to the ICU which is consistent with the findings of Joseph CM et al. [9]. Adverse outcome (mortality plus morbidity) was more in patients with Pregnancy induced hypertensive disorders, post-partum hemorrhage and sepsis which is consistent with conclusion by Sreenivas KS et al. [14]. In our study, all the 4 (2.5\%) patients admitted with septic encephalopathy and septic abortion had adverse outcomes (Table 3). According to Chawla et al. [15] patients admitted with post-abortal complications have features of infection, thereby showing the need for stricter implementation of the MTP Act and the need to provide easily available safe abortion services in our country. In our study 6 (3.8\%) patients underwent peripartum hysterectomy and required ICU admission. Jain S et al. [8] observed that women who underwent peripartum hysterectomy were at 5-fold increased risk of admission to ICU. Majority of the patient requiring ICU admission in our study were because of obstetric causes. However, heart disease was the only medical condition leading to admission of $13.8 \%$ patients in our study which was consistent with the findings of Jain et al. [8] who concluded that among the nonobstetric illness, cardiac disease (4.4\%) was the most common cause requiring ICU admission. Only one of our patients had peripartum cardiomyopathy and the patient was discharged in 13 days who required inotrope support and mechanical ventilation for 7 days. However, nonobstetric causes and other medical chronic comorbidities had no significant correlation with mortality in our study. Out of 160 patients in the study, most common pathological cause of ICU admission was hemorrhagic shock or anemia with 92 patients $(57.5 \%)$ followed by ventilatory support or monitoring with 51 patients (31.8\%). Out of the 51 patients, 22 (13.8\%) were of heart disease and were extubated mostly within 1 day or less. MODS and renal insufficiency had $3(1.8 \%)$ patients in each (Figure 5). Patients who underwent salpingectomy was higher in our study than Chawla et al16 who reported a proportion of $5.7 \%$. Salpingectomy and LSCS and had a good outcome overall. Out of the 160 study subjects, 145 patients $(90.6 \%)$ were discharged, 10 patients $(6.3 \%)$ expired and 5 patients $(3.1 \%)$ had comorbidity in terms of renal failure or neurological damage (Table 4).

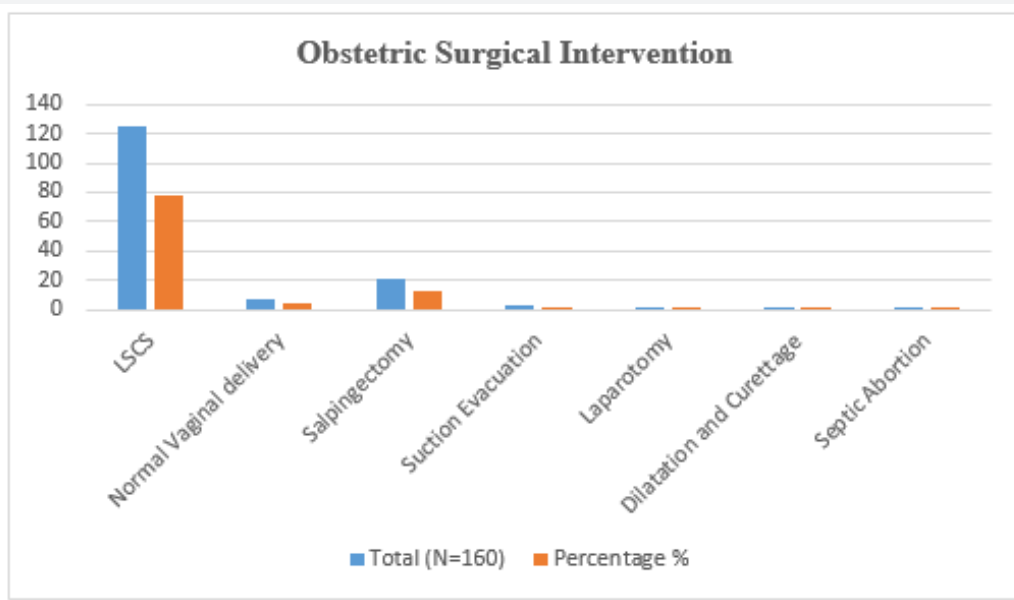

Figure 4: Distribution of study population $(\mathrm{N}=160)$ according to obstetric surgical intervention.

Table 4: Association of Prognostic Scores (MEWS and APACHE-II) and Outcome.

\begin{tabular}{|c|c|c|c|c|c|c|c|}
\hline \multirow{2}{*}{ SN } & \multirow{2}{*}{ Parameter } & \multicolumn{2}{|c|}{ Good Outcome (n=144) } & \multicolumn{2}{|c|}{ Adverse Outcome (n=15) } & \multicolumn{2}{|c|}{ Student 't' test } \\
\cline { 3 - 8 } & & Mean & SD & Mean & SD & ' $\mathbf{t}$ ' $\mathbf{p}$ ' \\
\hline 1 & MEWS & 3.76 & 2.38 & 8.20 & 2.62 & 6.829 & $<0.001$ \\
\hline 2 & APACHE-II & 12.60 & 5.03 & 19.20 & 5.19 & 4.823 & $<0.001$ \\
\hline
\end{tabular}

The mortality rate in our study, which was similar to Harde et al. [11] concluding a mortality rate of $6.557 \%$ and Sodhi et al. [16] who observed an overall mortality of $8.3 \%$. In our study, 112 $(70 \%)$ patients received mechanical ventilation in which 99 had good outcome (88\%) and $13(11 \%)$ had adverse outcome. The high ventilation rate in our study matches the Indian studies by Ashraf et al. [17] (85\%) and Jain et al. [8] (94.4\%) but is higher than that reported in many other Indian studies $[15,11]$. The tertiary referral center status of our hospital and prioritization of obstetric patients needing organ support for admission to our ICU are the reasons for a high ventilatory requirement in our study. In our study out of the total 160 patients, 14 (8.75\%) required the use of non-depolarizing muscle relaxant. NDMR usage was majorly for Acute Respiratory Distress syndrome in our study. Out of the 14, 4 had good outcome whereas 10 had adverse outcome. This difference was found to be statistically significant. In our study out of the total 160 patients, 114 (70\%) had requirement of blood products out of which 102 had good outcome whereas 13 had adverse outcome. It was the most common intervention done in our study. However, the association between use of blood 
products with outcome was found to be insignificant which is similar to the observation by Harde et al. [11]. In our study out of the total 160 patients, $73(45 \%)$ required the use of inotropes and the association between outcome and inotrope support was found to be statistically significant in our study. Pattnaik et al. [18] showed that $62.9 \%$ of patients required inotrope support. In our study, 20 patients had some end organ damage (kidney failure, neurological damage, MODS or ARDS) (Figure 6). In our study, 16 out of $160(10 \%)$ patients developed acute kidney injury requiring hemodialysis. These patients either recovered and got discharged or were discharged with comorbidity or had mortality. Similarly, study by Pattnaik et al. [18] observed a hemodialysis rate of $7.4 \%$. Study by Poornima B et al14 observed a hemodialysis rate of dialysis in $7.7 \%$ (Table 5 ).

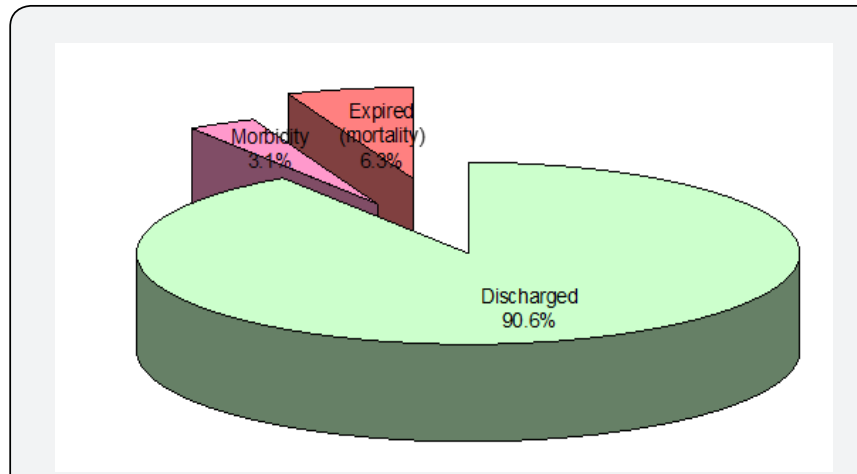

Figure 5: Distribution of Study Population $(\mathrm{N}=160)$ according to Outcome.

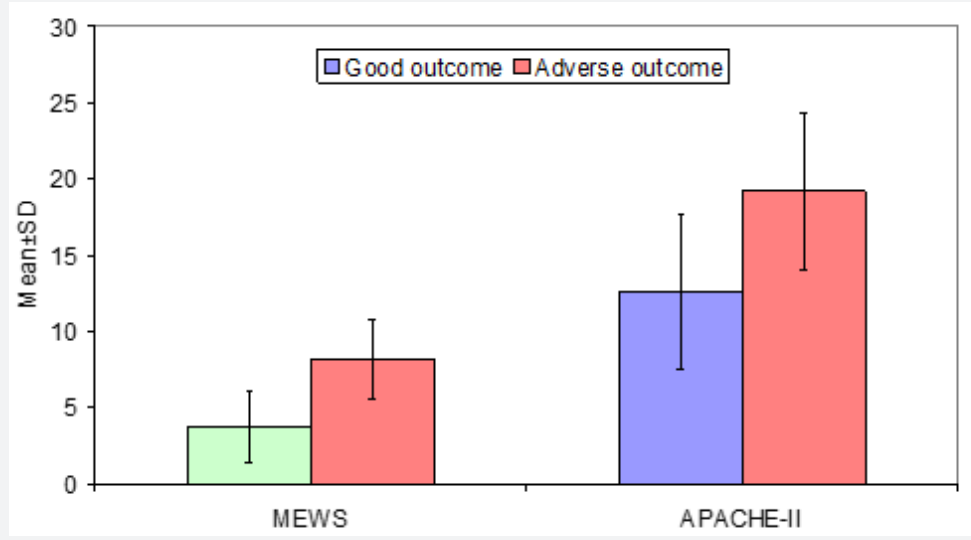

Figure 6: Association of Prognostic Scores (MEWS and APACHE-II) and Outcome.

Table 5: MEWS and APACHE II showing AUC to predict mortality and adverse outcome.

\begin{tabular}{|c|c|c|c|c|c|c|c|}
\hline \multirow{2}{*}{ SN } & \multirow{2}{*}{ Predicted outcome } & \multirow{2}{*}{ Prognostic Score } & \multirow{2}{*}{ Area Under Curve } & \multirow{2}{*}{ SE } & \multirow{2}{*}{ 'p' } & \multicolumn{2}{|c|}{$95 \% \mathrm{CI}$} \\
\hline & & & & & & Lower & Upper \\
\hline \multirow{2}{*}{1} & \multirow{2}{*}{ Mortality } & APACHE-II & 0.811 & 0.089 & $<0.001$ & 0.637 & 0.986 \\
\hline & & MEWS & 0.863 & 0.071 & $<0.001$ & 0.723 & 1.003 \\
\hline \multirow{2}{*}{2} & \multirow{2}{*}{ Adverse outcome (Mortality+ morbidity) } & APACHE-II & 0.822 & 0.061 & $<0.001$ & 0.703 & 0.942 \\
\hline & & MEWS & 0.888 & 0.050 & $<0.001$ & 0.790 & 0.985 \\
\hline
\end{tabular}

Table 6: Association of Outcome and APACHE-II score.

\begin{tabular}{|c|c|c|c|c|c|c|c|}
\hline \multirow{2}{*}{ SN } & \multirow{2}{*}{ APACHE-II Score } & \multirow{2}{*}{ Total (N=160) } & \multicolumn{2}{|c|}{ Good Outcome (n=145) } & \multicolumn{2}{|c|}{ Adverse Outcome (n=15) } & Predicted Mortality \\
\cline { 4 - 8 } & & & No. & $\mathbf{\%}$ & No. & \% & \% \\
\hline 1 & $0-4$ & 3 & 2 & 2.1 & 0 & 0.0 & 0 \\
\hline 2 & $5-9$ & 43 & 42 & 29.0 & 1 & 6.7 & 2.3 \\
\hline 3 & $10-14$ & 56 & 55 & 37.9 & 1 & 6.7 & 1.7 \\
\hline 4 & $15-19$ & 35 & 28 & 19.3 & 7 & 46.7 & 20 \\
\hline 5 & $20-24$ & 17 & 14 & 9.7 & 3 & 20.0 & 17.64 \\
\hline 6 & $25-29$ & 5 & 2 & 1.4 & 3 & 20.0 & 6 \\
\hline 7 & $30-34$ & 1 & 1 & 0.7 & 0 & 0.0 & \\
\hline
\end{tabular}

$x^{2}=27.828(d f=6) ; p<0.001$

Currently, there is no available literature on prognostic scores that are designed specifically for use in obstetric patients. APACHE

tend to overestimate mortality in obstetric patients [20]. So, our study was undertaken to evaluate and compare the predictability 
of two prognostic scores (APACHE II AND MEWS) used in ICU, out of which there has been no study on MEWS prognosticating obstetric population in the ICU. In our study, we observed that patients with adverse outcome as compared to those with good outcome had significantly higher prognostic scores i.e. MEWS score $(8.20 \pm 2.62$ vs. $3.76 \pm 2.38)$ and APACHE II $(19.20 \pm 5.19$ vs. 12.60 \pm 5.03 ) (Figure 7). Area under curve in ROC curve for APACHE-II and MEWS to predict the mortality were $0.811 \& 0.863$ whereas area under curve for APACHE-II and MEWS for prediction of adverse outcome (Mortality + Morbidity) were $0.822 \& 0.888$. According to Wang YM et al. [19], the area under the ROC curve for the MEWS system was greater than that of the APACHE II score. The difference in the area under the ROC curve between the MEWS and APACHE II scores in predicting the prognosis of the patients was statistically significant. This study showed that the MEWS system predicted the patient's prognosis with high resolution. Similarly, in our study, MEWS had a greater AUC than APACHE II for prediction of mortality as well as adverse outcome. The difference in AUC for MEWS and APACHE II was statistically significant (Figure 8). Therefore, MEWS predicted patient's prognosis with high resolution (Table 6). As shown in table also, MEWS has better association with adverse outcomes as compared to APACHE II. Adverse outcome was higher as compared to Good outcome in patients having APACHE-II score $\geq 15$. An APACHE II score of 20 points is the cut-off point for severity according to studies by Jiang XC et al. and HuB et al. [4,5] Majority of the patients having Good outcome had MEWS score <6.50 (84.8\%) while majority of the patients having Adverse outcome had MEWS score $\geq 6.50$ (86.7\%). This association was found to be statistically significant. Similarly, MEWS was also studied by A. Oscarsson et al. [7] in ICU to predict mortality. They concluded that a MEWS score of 5 or above at admission was associated with an increased risk of ICU death. According to Wang YM et al. [19], the APACHE II score can be used to predict the prognosis of patients, but its ability to distinguish among patients is moderate (Figure 9) (Table 7).

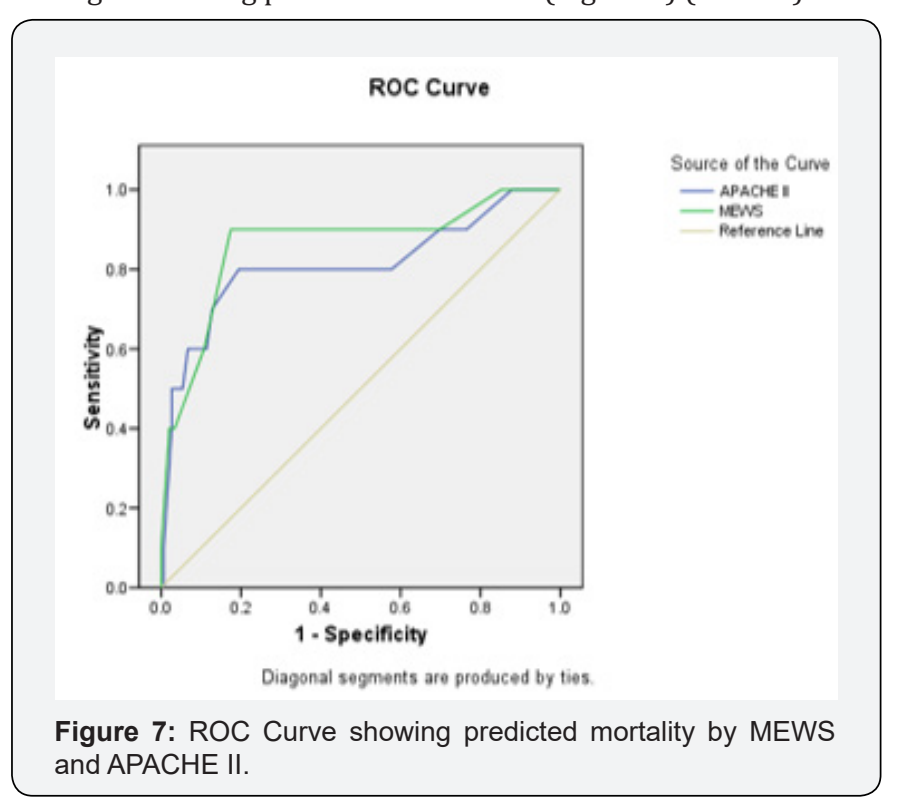

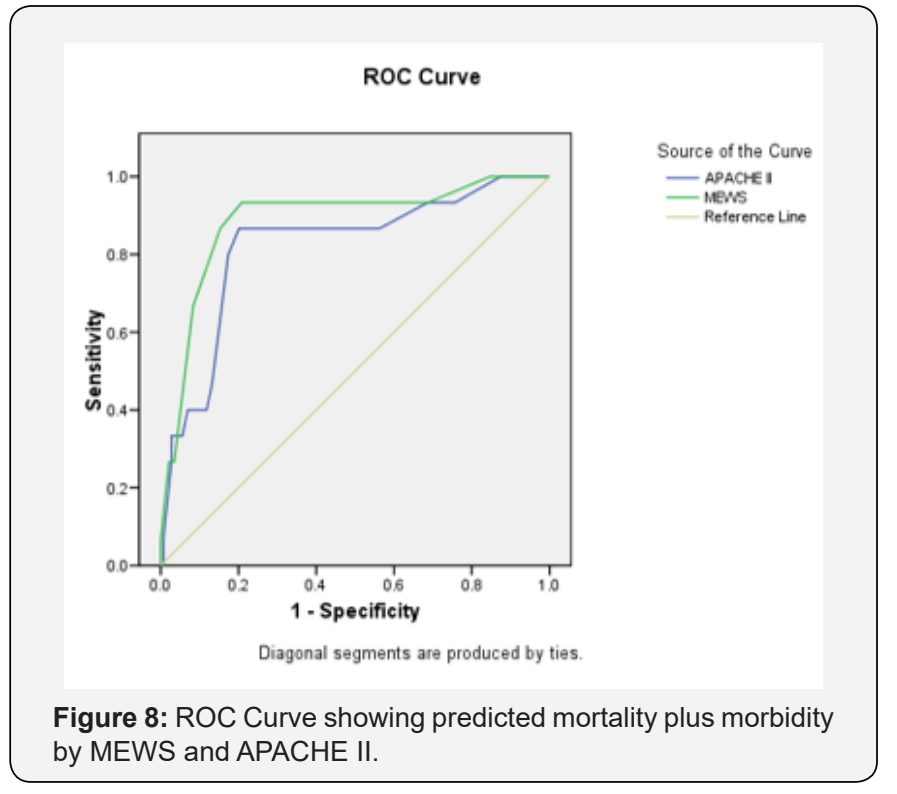

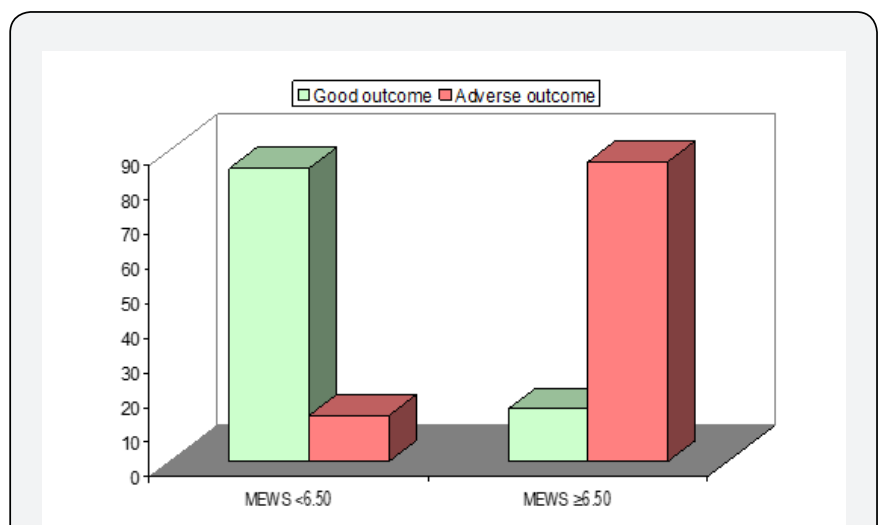

Figure 9: Association of Outcome and MEWS cut-off.

Table 7: Association of Outcome and MEWS cut-off.

\begin{tabular}{|c|c|c|c|c|c|c|}
\hline \multirow{2}{*}{ SN } & \multirow{2}{*}{$\begin{array}{c}\text { MEWS } \\
\text { Cut-off }\end{array}$} & \multirow{2}{*}{$\begin{array}{c}\text { Total } \\
(\mathbf{N = 1 6 0 )}\end{array}$} & \multicolumn{2}{|c|}{\begin{tabular}{c}
\multicolumn{2}{|c|}{ Good Outcome } \\
$\mathbf{( n = 1 4 5 )}$
\end{tabular}} & \multicolumn{2}{|c|}{$\begin{array}{c}\text { Adverse } \\
\text { Outcome } \\
(\mathbf{n = 1 5})\end{array}$} \\
\cline { 4 - 7 } & & No. & $\%$ & No. & $\%$ \\
\hline 1 & $\begin{array}{c}\text { MEWS } \\
<6.50\end{array}$ & 125 & 123 & 84.8 & 2 & 13.3 \\
\hline 2 & $\begin{array}{c}\text { MEWS } \\
\geq 6.50\end{array}$ & 35 & 22 & 15.2 & 13 & 86.7 \\
\hline
\end{tabular}

\section{Conclusion}

Obstetric patients require Intensive care unit and High Dependency Unit because they are a direct indicator of the health status of the country. Pregnancy Induced Hypertension was major cause of postpartum obstetrical ICU admissions in our study and it had an adverse prognosis overall. Our study focused on validity of an easier prognostication score on such patients so that we can focus on the high-risk patients and improve overall survival of this population. In the study, MEWS score had a better sensitivity and specificity than APACHE II. Thus, it can be concluded from our study that MEWS is a better indicator of prognosis than APACHE 
II, which is also more time consuming and laborious, in critically ill obstetric patients.

\section{References}

1. Jamal S, Mehta A, Goel N, Ahuja M, Afreen N, et al. (2018) Obstetrics ICU admissions: challenges faced at a tertiary referral centre. IJRCOG 7(5): 1840-1843.

2. Moseson EM, Zhuo H, Chu J, Stein JC, Matthay MA, et al. (2014) Intensive care unit scoring systems outperform emergency department scoring systems for mortality prediction in critically ill patients : a prospective cohort study. J Intensive Care 2: 40.

3. Ryan HM, Sharma S, Magee LA, Ansermino JM, MacDonell K, et al. (2016) The Usefulness of the APACHE II Score in Obstetric Critical Care : A Structured Review. J Obstet Gynaecol Can 38(10): 909-918.

4. Jiang XC (2000) Clinical application and significance of critical illness severity score. Chin Crit Care Med 12: 195-197.

5. Hu B, Duan ML, Li A, Liu C (2008) The occurrence of stress ulcer in critically ill patients with APACHE relationship between score and prognosis of patients. Shandong Med 48: 6-9.

6. Khwannimit B, Bhurayanontachai R, Vattanavanit V (2019) Comparison of the accuracy of three early warning scores with SOFA score for predicting mortality in adult sepsis and septic shock patients admitted to intensive care unit. Heart Lung 48(3): 240-244.

7. Reini K, Fredrikson M, Oscarsson A (2008) The prognostic value of the Modified Early Warning Score in critically ill patients: a prospective, observational study. Eur J Anaesthesiol 29(3): 152-157.

8. Jain S, Guleria K, Vaid NB, Suneja A, Ahuja S (2016) Predictors and outcome of obstetric admissions to intensive care unit: A comparative study. Indian J Public Health 60(2): 159-163.

9. Joseph CM, Bhatia G, Abraham V, Dhar T (2018) Obstetric admissions to tertiary level intensive care unit-Prevalence, clinical characteristics and outcomes. Indian J Anaesth 62(12): 940-944.

10. Dasgupta S, Jha T, Bagchi P, Singh SS, Gorai R, et al. (2017) Critically ill obstetric patients in a general critical care unit: A 5 years' retrospective study in a public teaching hospital of Eastern India. Indian J Crit Care Med 21(5): 294-302.

This work is licensed under Creative Commons Attribution 4.0 License

DOI: 10.19080/JAICM.2019.10.555776
11. Harde M, Dave S, Wagh S, Gujjar P, Bhadade R, et al. (2014) Prospective evaluation of maternal morbidity and mortality in post-cesarean section patients admitted to postanesthesia intensive care unit. J Anaesthesiol Clin Pharmacol 30(4): 508-513.

12. Gupta S, Naithani U, Doshi V, Bhargava V, Vijay BS (2011) Obstetric critical care: A prospective analysis of clinical characteristics, predictability, and fetomaternal outcome in a new dedicated obstetric intensive care unit. Indian J Anaesth 55(2): 146-153.

13. Bhat PB, Navada MH, Rao SV, Nagarathna G (2013) Evaluation of obstetric admissions to intensive care unit of a tertiary referral center in coastal India. Indian J Crit Care Med 17(1): 34-37.

14. Sreenivas KS, Beevi AN, Devi NU (2014) Clinical Characteristics and Outcome of Obstetric Patients Who Required Mechanical Ventilation in a Tertiary Care Hospital in North Kerala. Indian J Clinic Prac 25(6): 552-557.

15. Chawla S, Nakra M, Mohan S, Nambiar BC, Agarwal R, et al. (2013) Why do obstetric patients go to the ICU? A 3-year-study. Med J Armed Forces India 69(2): 134-137.

16. Sodhi K, Bansal V, Shrivastava A, Kumar M, Bansal N (2018) Predictors of Mortality in Critically Ill Obstetric Patients in a Tertiary Care Intensive Care Unit: A Prospective 18 Months Study. Jour obster anes and crit care 8(2): 73-78.

17. Ashraf N, Mishra SK, Kundra P, Veena P, Soundaraghavan S, et al. (2014) Obstetric patients requiring intensive care: a one-year retrospective study in a tertiary care institute in India. Anesthesiol Res Pract.

18. Pattnaik T, Samal S, Behuria S (2015) Obstetric admissions to the Intensive Care Unit: A five year review. Int J Reprod Contracept Obstet Gynecol 4(6): 1914-1917.

19. Wang YM, Wei TT, Hou M, Zhang L, Li P (2017) Comparative research on the prognostic ability of improved early warning and APACHE II evaluation for hospitalized patients in the emergency department. Chinese Nursing Research 4(1): 38-42.

20. Hazelgrove JF, Price C, Pappachan VJ, Smith GB (2001) Multicenter study of obstetric admissions to 14 intensive care units in southern England. Crit Care Med 29(4): 770-775.

\section{Your next submission with Juniper Publishers} will reach you the below assets

- Quality Editorial service

- Swift Peer Review

- Reprints availability

- E-prints Service

- Manuscript Podcast for convenient understanding

- Global attainment for your research

- Manuscript accessibility in different formats

( Pdf, E-pub, Full Text, Audio)

- Unceasing customer service

Track the below URL for one-step submission https://juniperpublishers.com/online-submission.php 